Original Research Paper

\title{
Perceptions of Care, Socio-Demographic Characteristics and Health Care Utilisation among Health Insurance users in Ghana
}

\author{
Seth Christopher Yaw Appiah \\ Department of Sociology and Social Work, Faculty of Art and Social Sciences, \\ Kwame Nkrumah University of Science and Technology, Kumasi, Ghana
}

Article history

Received: 14-12-2014

Revised: $29-12-2014$

Accepted: 23-06-2015

\begin{abstract}
The socio-demographic characteristics of clients and their perception of quality of care play a major part in people's decision making process especially in service utilization. This study assesses the relationship between clients' socio-economic features as well as their perceived quality on health care utilization. The study adopted a nonexperimental cross sectional design in eliciting information from health clients who accessed health services in ten selected hospitals in the Kumasi Metropolis with a cluster sampling design to select 400 clients from the ten health facilities purposely selected. The researcher used interviews and semi structured questionnaires to collect data and used SPSS version 20 for processing whiles descriptive and inferential statistics was supported with STATA 11. Perception about the quality of health provision influenced access of healthcare with NHIS cards. Clients who viewed the overall quality of health provision as good or very good were more likely to access healthcare with NHIS card as compared to those who rated the overall health provision as poor or very poor $(\mathrm{OR}=2.1 ; \mathrm{p}<0.01)$. Socio-demographic factors continuously play a strong role in influencing clients to access health care under the National Health Insurance Scheme (NHIS) as the high income groups still dominate in utilizing health care services under the scheme than the deprived and the poor. Increased enrolment in the scheme should be supported with provision of quality services to enhance clients' satisfaction. Also, socio-demographic characteristics influence the utilization of health care.
\end{abstract}

Keywords: Ghana, Health Insurance, Perception, Health Care, Utilization, Socio-Demographic

\section{Introduction}

In 2003, the National Health Insurance Scheme (NHIS) was established under Act 650 of 2003 by the Government of Ghana with the objective of providing basic healthcare services to Ghanaians through mutual and private health insurance schemes (Boateng and Awunyor-Vitor, 2013). The National Health Insurance Scheme (NHIS) came into effect in 2004 at a time when out of $80 \%$ of patients who required health care at any given time, only twenty percent had access to health care
(Assensoh and Wahab, 2008) aimed at offering affordable and quality health care services to Ghanaians.

In Agyei-Baffour et al. (2013) study, despite the improvements in quality health care that the National Health insurance Scheme is facilitating in Ghana, there still continue to exist implementation challenges necessitating for proper reforms. Several factors aid in defining and understanding the drivers of health service utilization especially among health insured clients.

The Socio-Demographic characteristics consider the location of the people, their income levels, 
religion, educational levels, ethnicity and other social and cultural factors.

Several studies have documented on the influence of socio-demographic factors on membership renewal and subscription into NHIS (Basaza et al., 2008; Dalinjong and Laar, 2012; Dong et al., 2009; Nketiah-Amponsah, 2009; Sarpong et al., 2010). Buor (2004) in his study report that closeness to the scheme office was preferred to than when it was farther. This is further supported by Boateng and Awunyor-Vitor (2013) in their study in the Volta region of Ghana with their findings showing $72 \%$ disapproving of the convenience of the scheme office location. It was noted in all the studies by De Allegri et al. (2006a; 2006b; Sinha et al., 2006; Kamuzora and Gilson, 2007; Ndiayec et al., 2007; Asante and Aikins, 2008) the relationship different demographic factors has with NHIS enrollment and subsequent renewal of membership.

The findings from Aryeetey et al. (2010) cross sectional study of a sample population of 13, 867 individuals, with an average of 25 years and children under 18 years representing $49 \%$ of the sample, show that despite the fact that $67 \%$ of all individuals were in some form of employment, education which was measured by total years of schooling was low at a mean of 7 years whiles the mean monthly individual income was GHф43.70 (US\$29). This amount is thrice of what is required to renew NHIS membership. To the authors, this presents a difficult situation for most people since the average annual cost of premiums per individual is GH $\$ 14.00$ with an additional registration fee of GH $\notin 3.00$. Unaffordability of premiums was cited as the most common reason for not enrolling $(72 \%)$ and not renewing membership (61\%).

Demographic variables continue to feature prominently as a major determinant to renewal of membership. Among the reported studies, socioeconomic factors which have association with NHIS enrollment and service utilization are gender as reported by Boateng and Awunyor-Vitor (2013), marital status in the study of Boateng and Awunyor-Vitor (2013; Trujillo, 2003; Liu and Chen, 2002) and occupation as indicated in the findings of Butler (1999; Savage and Wright, 1999) where employed respondents were found to be more likely to undertake coverage than unemployed. In a study by Boateng and Awunyor-Vitor (2013), gender was a significant determinant of one's insurance status; however no significant association was established between occupation, educational status and enrollment in NHIS. Whiles health status has been found to be associated with NHIS enrollment decision as reported by (Boateng and Awunyor-Vitor, 2013), findings by (De Allegri et al., 2006a) in Burkina Faso suggest contrary.

In WHO (2010) study, one issue of concern regarding the refusal of members to renew their cards was the levels of incomes (Butler, 1999). The study indicated that people living in the remote, underserved areas of the country who are low income earners may not perceived the benefits of membership in the light of their low levels of income (Basaza et al., 2008; Bruce et al., 2008). Thus, though they appreciate the benefits of enrollment, they lack ability to enroll due to their poverty levels.

As indicated by (WHO, 2010), 88\% of urban dwellers who have higher incomes agreed that they were ever willing to renew their cards. This is compared with only $57 \%$ of their counterparts in the rural centres. This is also supported by National Development Planning Commission (NDPC) (NDPC, 2009) finding that the level of registration in urban centres is $10 \%$ higher than the rural centres. Similarly, the strict income norm for exempting the poor actually excluded the marginal poor, who are not able to pay the premium; in some cases, an International Labour Organization (ILO) programme and some Non-Governmental Organization (NGOs) stepped in to pay the premium on their behalf. Not all children (under 18 years) could be covered because of the condition that their parents have to be insured first. However, Boateng and Awunyor-Vitor (2013) study presents a contrary finding as poverty levels did not constitute a problem for health insurance subscribers as earlier studies by (Basaza et al., 2008; Bruce et al., 2008) suggested for insurance in low-income countries like Uganda and Ghana. During the commencement of the National health insurance in some areas, people refused to enroll themselves into the scheme due to political differences instead of the benefits that accrued from the scheme. This is however, gradually changing as many have realized the significance of the scheme to their health needs (WHO, 2010).

The socio-demographic characteristics of patients have well been established as instrumental factor that influence the utilization of health care (Buor, 2004). Other researchers attest to the relationship that sociodemographic factors has with health care utilization than any other factor in influencing client's access to health care under the NHIS (Basaza et al., 2008; Dalinjong and Laar, 2012; Dong et al., 2009; Nketiah-Amponsah, 2009; Asante and Aikins, 2008). However, emphasis on addressing only socio-demographic factors such as levels of income, occupations, marital status and age in order to ensure health care utilization seems to be fading.

The Ministry of Health (MOH) in Ghana has been concerned about quality of care, but improvements in quality have been slow partly because quality improvement activities have received inadequate priority (Haran et al., 2000). Other researchers (Boateng and Awunyor-Vitor, 2013; Wiesmann and Jütting, 2001; Asenso-Okyere et al., 1997) think that, due considerations should also be given to clients' perceived perception of care since it plays influential 
roles in health care utilization under the scheme. For instance (Alatinga and Williams, 2012), observed that the insured in NHIS think that the uninsured are generally given quality drugs as compared to them. Among the drugs perceived to be of inferior quality were Paracetamol, a common painkiller that can easily be bought over the counter. In the opinion of (De Allegri et al., 2006b; Lee et al., 2011; Turkson, 2009), quality can only be achieved by ensuring clients' participation and proper assessment about perception about quality of care.

Patient's perception of quality of care is critical in understanding the relationship between quality of care and utilization of health services and thus, should never be ruled out (Ross and Mirowsky, 2000). Though, clients' perceptions have been researched into by scholars such as (Lee et al., 2011; Turkson, 2009), others including (Arhinful, D., 2003; Akazili et al., 2005) admit that studies regarding perceptions about quality of health care and their impact on decisions to enroll into the scheme in Ghana are still limited. In (Boateng and Awunyor-Vitor, 2013) study, respondents reported negative perceptions about the technical quality of care and the adequacy of service delivery. Perceptions about quality were not limited to only technical, but also attitude of doctors and nurses. According to them this influenced the decision of respondents to renew NHIS policy.

Notwithstanding the limitedness of research on examining client perception of quality of care, there is generally a difficulty in defining quality of care. The WHO (2006) conceptualizes quality of care as one that has the features of being effective; thus the health care offered that is adherent to an evidence base and results in improved health outcomes for individuals and communities, based on need. The definition examines efficiency which concerns delivering health care in a manner which maximizes resource use and avoids waste. Added to efficiency is that the service has to be accessible; delivering health care that is timely, geographically reasonable and provided in a setting where skills and resources are appropriate to medical need. Quality of care equally examines the acceptable/patient-centred nature of the health care delivery focusing on the preferences and aspirations of individual service users and the cultures of their communities. The health care delivery must be seen to be equitable, thus not varying in quality because of personal characteristics such as gender, race, ethnicity, geographical location or socioeconomic status (Buor, 2004; Preker and Carrin, 2004). It is one that is safe as it delivers care that minimizes risks and harm to service users. The dimensions of quality of care depict the variants in what constitute quality of care for health care users. While some study report an even provision of care in terms of quality for both insured and noninsured, the study by (Devadasan et al., 2004; Dalinjong and Laar, 2012) reports that those insured clients were being attended to better than those uninsured. The objective of this paper is to examine socio-demographic characteristics as well as perceptions of care by NHIS card bearers and their relationship with access to healthcare with NHIS card.

\section{Materials and Methods}

\section{Research Setting and research Design}

The study employed a cross-sectional study design using quantitative research approach. The study location was the Bantama and Kwadaso Sub Metro Councils. The Bantama Sub Metro Council is located at the north-western part of the Kumasi Metropolis. It shares boundary to the north with Atwima Nwabiagya District Assembly, to the east with Suame, Tafo and Asawase Sub-Metropolitan Councils to the west with and to the south with Subin and Nhyiaeso Sub-Metro Council. Bantama was one of the first Submetropolises formed in 1995. With the creation of ten Sub-Metros in the Kumasi Metropolis in 2007, Kwadaso and Nhyiaeso were carved out of the former Bantama Sub-Metro. Bantama is one of the centres of the Asante history. Traditionally, Bantama is one of the principal traditional Stools in the Ashanti Kingdom. According to the demarcations of the National Health Authority, Bantama Sub-Metro is made up of three Sub Metros namely, Bantama SubMetro, Kwadaso Sub-Metro and Nhyiaeso Sub-Metro. The population of the Sub Metro Council is about 533,464 according to the Ghana Statistical service. The selection of the Bantama Sub metro is premised on the fact that it is the biggest scheme in Kumasi in terms of the number of subscribers and the number of accredited health service providers Bantama has mixed geographical features of urban, rural (as defined by having population less than 5000) and periurban. Again, the sub-metro has all the various provider types and levels under the NHIS. The Bantama Sub Metro play host to the Komfo Anokye Teaching Hospital (KATH), one of the two (2) national autonomous hospitals, Suntreso hospital, Kumasi South and Maternal and Child Health and other clinics offering generalist and specialized health service. The Kwadaso Sub Metro Council constituted the study setting. The Kwadaso Sub Metro Council was curved out from Bantama Sub metro. It is located in the western part of Kumasi and shares boundary with Atwima Nwabiagya (Nkawie) to the north, Bantama to the South Nhiaeso to the east and the Atwima Kwawoma (Ofoase) to the west. The sub metro council comprises fifteen communities which 
are sub-divided into nine (9) electoral areas. It has a population of 220,798 according to the 2010 population and housing census. (GSS, 2010) In terms of health care access, the two sub metros utilize the same health facilities since they occupy the same land area but have been divided for administrative purpose.

\section{Study Population and Sampling}

Multistage sampling technique was used to select respondents for the study. The researcher purposively selected the Ashanti region out of 10 administrative regions in Ghana after which the Kumasi Metropolis selected. The Bantama and Kwadaso Sub Metro Council were randomly selected from the nine Sub Metro Councils which make up the Kumasi Metropolis. At the stage two, the two areas were divided into five clusters representative of the location of the various hospital within the Sub metro districts. Two hospitals each totaling ten (10) was selected at random within the cluster areas. The researcher selected Insured National Health Insurance subscribers accidentally at the hospital premises as they waited to receive medical attention. In all, a sample of 400 clients was selected for the study. All NHIS policy holders aged 18-70 years who gave their consent to participate in the study were eligible. The proportion of the population with the outcome attribute, thus insured NHIS clients, was taken as 50\% (0.5), with a \pm 1.96 at $95 \%$ Confidence Level. The Sample Size was calculated to be 384 . This calculation was based on this formula: The arrival of the sample size was on the formula:

$\mathrm{n}=\mathrm{Z} 2(\mathrm{P})(\mathrm{q}) / \mathrm{d} 2$.

$\mathrm{n}=$ the desired sample size

$\mathrm{z}=$ the standard normal deviation 1.96

$\mathrm{p}=$ the proportion in the target population who access health care with their NHIS card 50\% (0.50)

$\mathrm{q}=1.0-\mathrm{p}$

$\mathrm{d}=$ degree of accuracy desired at 0.05

$\mathrm{n}=(1.96) 2(0.5)(0.5)(0.05) 2$

$\mathrm{n}=384$

The researcher made provision for $10 \%$ nonresponse; $384+20=404$. The sample size was adjusted by $1 \%$ design effect reaching a sample size of 407.2. The researcher found seven of the responses lacking clarity and inconsistent and had to be taken discarded from being included. The total sample size for the study was 400 .

\section{Data Collection and Statistical Analysis}

The study used questionnaire in collecting data. Information on study participants included enrollment in National Health Insurance, NHIS renewal status and personal socio-demographic characteristics. The questionnaires was structured to elicit information such as age, gender, occupation, education, monthly income, marital status, self-perceived health status and perceptions of quality of care and NHIS. The questionnaire was pre-tested at the Tafo Government Hospital to check for internal consistency and absence of ambiguity and later edited. Content validity was carried out to test for the validity of the findings. External validity of the study was performed by comparing the findings to the extant literature.

The study's response rate was had $98 \%$. The study had two dependent variables; Health Care access and Utilization, the other was Perception of care). Whether subscriber had ever accessed healthcare under NHIS with the response $\{\mathrm{Yes}=1 ; \mathrm{No}=2\}$ was the primary indicator for measuring dependent variable 'health care access and utilization'. The dependent variable; Perception of care had overall satisfaction of health care with the likert scale response ranging from Excellent, Very Good, Good, Average, Poor, to very Poor as its Primary indicator for measuring. The selection of demographic variables was based on the extant literature. The demographic variables of age, sex, education, marital status, occupation, place of residence were examined.

\section{Ethical Considerations}

The researcher sought clearance from the University Ethical committee. Permission was sought from the administrators of all the hospitals involved in the study. Informed consent was obtained from the insured clients to obtain data for the study. Participation in the study was voluntary and anonymous.

\section{Results}

Table 1 presents the socio-demographic characteristics of clients involved in this study. The mean age of the respondents was 30 years $(+11)$ and $41.5 \%$ of the respondents were below age 25 years. Only $10.1 \%$ of the respondents were above age 44 . Majority, $50.6 \%$ were females and about $13.5 \%$ of the respondents had no form of education while almost $45 \%$ of them have had tertiary education. Majority, $56.9 \%$ of the respondents were single whereas $36.3 \%$ were married. More than half of the respondents, $51.0 \%$ of the respondents were students or unemployed whereas about $24.7 \%$ of them were traders. Other occupations cited among respondents included accountants, bankers, drivers, farmers, health workers and seamstress. Most $(64.5 \%)$ of the respondents involved in the study were urban dwellers and majority $54.5 \%$ of the respondents have been members of the NHIS for a period between 3 and 5 yrs. 
Table 1. Socio-demographic characteristics of respondents

\begin{tabular}{|c|c|c|}
\hline Variables & Frequency & Percentage $(\%)$ \\
\hline \multicolumn{3}{|l|}{ Age $(n=398)$} \\
\hline$-<25$ & 165 & 41.50 \\
\hline$-25-34$ & 127 & 31.90 \\
\hline$-35-44$ & 66 & 16.60 \\
\hline$->44$ & 40 & 10.10 \\
\hline Mean (SD) & $30(10.5)$ & \\
\hline \multicolumn{3}{|l|}{ Gender $(n=399)$} \\
\hline - Male & 19749.4 & \\
\hline -Female & 20250.6 & \\
\hline \multicolumn{3}{|l|}{ Education $(n=391)$} \\
\hline - No school & 53 & 13.50 \\
\hline - Junior High school & 39 & 10.00 \\
\hline - Senior High school & 125 & 32.00 \\
\hline - Tertiary education & 174 & 44.50 \\
\hline \multicolumn{3}{|c|}{ Marital status $(n=399)$} \\
\hline - Single & 227 & 56.90 \\
\hline - Married & 145 & 36.30 \\
\hline - Widowed & 27 & 6.80 \\
\hline \multicolumn{3}{|l|}{ Occupation $(n=365)$} \\
\hline - Trading & 90 & 24.70 \\
\hline - Student/unemployed & 186 & 51.00 \\
\hline - Teaching & 75 & 20.60 \\
\hline - Other & 14 & 3.80 \\
\hline \multicolumn{3}{|c|}{ Residence Pattern $(n=389)$} \\
\hline - Urban & 251 & 64.50 \\
\hline - Rural & 138 & 35.50 \\
\hline \multicolumn{3}{|c|}{ How long been a member of NHIS $(n=389)$} \\
\hline$-<1$ year & 10 & 2.57 \\
\hline - 1-2years & 113 & 3.34 \\
\hline - 3-5years & 212 & 54.49 \\
\hline - >5years & 54 & 13.88 \\
\hline
\end{tabular}

The Fig. 1 indicates the graphical presentation of accessing healthcare with NHIS card by the respondents involved in the study. Majority $92 \%$ $(368 / 400)$ of the respondents reported to have accessed healthcare with their cards at least once. Only $8 \%$ of them had never accessed healthcare with their NHIS card since they registered with the scheme. Majority $40.7 \%(150 / 368)$ of the respondents attributed the failure to use their cards to access health due to the fact that they normally do not fall sick. Other reasons cited were recently registered and low quality of healthcare under NHIS as shown in Fig. 2.

Table 1 presents a bivariate analysis of the relationship between respondents' socio-demographic characteristics on their utilization of healthcare with the NHIS card. Only occupation (being a student or unemployed) and place of resident of the respondent had significant association with utilisation of health care. As compared to being a trader, respondents who were students or unemployed had less odds of accessing healthcare with their NHIS cards $(\mathrm{OR}=0.2$; $\mathrm{p}<0.0$. Most $(64.5 \%)$ of the respondents involved in the study were urban dwellers and majority $54.5 \%$ of the respondents have been members of the NHIS for a period between 3 and 5 yrs. Again residing in a rural part of the Sub Metro's decreased one's likelihood of accessing healthcare with NHIS card as compared to those who resided in urban area $(\mathrm{OR}=0.4 ; \mathrm{p}<0.05)$. The age, gender, education and marital status of respondents had no significant relationship.

The perceptions of respondents about the quality of care and attitude of health staff influenced their decision to access health care with their NHIS cards. Not being informed about health condition by the physician and not informing client whether to return to facility or not significantly decreased the likelihood of accessing healthcare with their NHIS cards. Clients who viewed health providers' skills as good or very good were 1.9 times more likely to access healthcare with NHIS card as compared to those who viewed service providers' skills as poor or very poor (OR = $1.9 ; \mathrm{p}<0.01)$. Finally, clients who viewed the overall health provision as good or very good were 2.1 times more likely to access healthcare with NHIS card as compared to those who rated the overall health provision as poor or very poor $(\mathrm{OR}=2.1$; $<<0.01)$. This is depicted in Table 3.

The Table 4 presents a stepwise regression analysis of the factors influencing decision to access healthcare with NHIS card. It involves the influence of socio-demographic analysis on accessing healthcare with NHIS card (model 1) as well as the combined influence of the socio-demographic characteristics and perceptions about health provision. In model 1 , being a student or unemployed decreased the odds of accessing healthcare with NHIS card as compared to being a trader and this relationship was again observed in model 2.

Again residing in a rural part of the Sub Metro's significantly reduced the likelihood of accessing healthcare with NHIS card (OR $=0.4 ; \mathrm{p}<0.05)$ and this relationship was again observed in model 2 , holding all variables constant. With the exception of providers' respect for clients' views, the perceptions about healthcare did not significantly influence clients' decision to access healthcare with NHIS in the multivariate analysis.

The summary of perceptions about attitudes of health personnel's in respect of dealing with NHIS subscribers is presented in Table 5 . About $25 \%$ of the respondents strongly disagreed that healthcare provider's accord much respect to NHIS clients compared with non-insurers while only about $10 \%$ of the respondents strongly agreed to this. Majority (93.4\%) of the respondents indicated that, service providers have time to listen to their problems. Only $(10.5 \%)$ of the respondents revealed that, service 
providers are not sensitive to their request and complaints. About $49 \%$ of the respondents rated overall attitude of NHIA service persons as good whereas only $3.6 \%$ indicated that their attitude was very poor. About $83.6 \%$ of the respondents said they will recommend the services of the service.

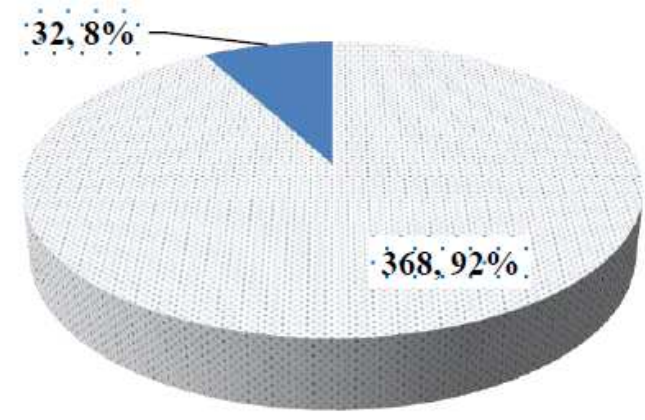

$\therefore$ Ever accessed healthcare under NHIS

Never accessed healthcare under NHIS

Fig. 1. Accessing health care with NHIS card



Fig. 2. Reasons why client is not accessing healthcare with NHIS Card

Table 2. Results of bivariate analysis of relationship between socio-demographic characteristics and accessing health with NHIS card Variables Odds ratio $95 \% \mathrm{CI}$

Age $(\mathrm{ref}=<25)$

- 25-34 1.9

$0.8,4.6$

$-35-44$

2.7

$0.8,9.7$

$->44$ $0.6,11.1$

Sex $($ ref $=$ Male $)$ Education $($ ref $=$ No school $)$

- Junior High school

- Senior High school

- Tertiary education

Marital status (ref $=$ Single)

- Married

$1.1,6.9$

- Widowed

Occupation $($ ref $=$ Trading

Student/unemployed Teaching

- Other

Place of residence (ref=Urban)

- Rural

$0.4 *$

Outcome $=$ Health Utilisation with NHIS card; ${ }^{*} \mathrm{p}<0.05 ; * * \mathrm{p}<0.01 ; * * * \mathrm{p}<0.001$ 
Table 3. Socio-demographic factors and health care access under the NHIS card

\begin{tabular}{lll}
\hline Variables & Odds ratio & $95 \%$ CI \\
\hline Were you examined by the Doctor/ MA? (ref= yes) & 0.4 & $0.1,1.9$ \\
Were you informed about your condition by the Doctor/MA? (ref = yes) & $0.2^{* *}$ & $0.1,0.6$ \\
Whether Doctor/MA gave instructions about condition? (ref = yes) & 0.3 & $0.1,1.1$ \\
Did Doctor/MA tell you whether or not you need to return? (ref = yes) & $0.2^{* * *}$ & $0.1,0.5$ \\
Existence of consultative privacy? (ref = yes) & 0.9 & $0.3,2.9$ \\
Acceleration of service (ref = very poor/poor) & 1.4 & $0.9,2.1$ \\
Provider competence (ref = very poor/poor) & $1.9^{* *}$ & $1.3,3.0$ \\
Client focus and respect (ref = very poor/poor) & $1.5^{*}$ & $1.0,2.2$ \\
Health client concerns and complains (ref = very poor/poor) & 0.9 & $0.6,1.4$ \\
Overall satisfaction of health care (ref = very poor/poor) & $2.1^{* *}$ & $1.3,3.3$
\end{tabular}

Outcome $=$ Health Utilisation with NHIS card; $* \mathrm{p}<0.05 ; * * \mathrm{p}<0.01 ; * * * \mathrm{p}<0.001$

Table 4. Multivariate analysis of factors determining decision to access healthcare with NHIS card

\begin{tabular}{lll}
\hline Variables & $\begin{array}{c}\text { Model 1 } \\
\text { OR (95\% CI) }\end{array}$ & $\begin{array}{c}\text { Model 2 } \\
\text { OR (95\% CI) }\end{array}$ \\
\hline SOCIO-DEMOGRAPHIC VARIABLES & & \\
Occupation (ref = Trading) & $0.2(0.1,0.8)^{*}$ & $0.2(0.1,0.8)^{*}$ \\
- Student/unemployed & $0.2(0.05,1.2)$ & $0.2(0.04,1.1)$ \\
- Teaching & $0.4(0.2,0.9)^{*}$ & $0.3(0.1,0.8)^{*}$ \\
Client residency pattern (ref = Urban) & & $0.5(0.1,2.0)$ \\
SERVICE QUALITY AND PATIENT ATISFACTION & & $0.5(0.2,1.5)$ \\
Client informed about condition by attending health officer? (ref = yes) & & $1.2(0.7,2.2)$ \\
Information to client to come for health review? (ref=yes) & & $1.4(1.1,2.4)^{*}$ \\
Service provider skill (ref = very poor/poor) & & $1.3(0.7,2.5)$ \\
Autonomy/Respect for client's views (ref= very poor/poor) & 329 \\
Overall satisfaction of health care (ref = very poor/poor) & 340 & 329 \\
N & -86.676 & 0.001 \\
Log likelihood & -76.623 & 0.001 \\
Prob>chi & &
\end{tabular}

Table 5. Patient assessment of service quality

\begin{tabular}{|c|c|c|}
\hline Variables & Frequency & Percent \\
\hline \multicolumn{3}{|c|}{$\begin{array}{l}\text { Comparism of respect accorded by Healthcare providers } \\
\text { for NHIS clients compared with the non-insured }(\mathrm{n}=392)\end{array}$} \\
\hline - Strongly agree & 38.0 & 98.0 \\
\hline - Agree & 81.0 & 20.7 \\
\hline - Indifferent & 40.0 & 10.2 \\
\hline - Disagree & 135.0 & 34.4 \\
\hline - Strongly disagree & 9.7 & 25.0 \\
\hline \multicolumn{3}{|c|}{$\begin{array}{l}\text { Whether service providers have time to listen to client } \\
\text { problems? }(n=391)\end{array}$} \\
\hline - Yes & 365.0 & 26.0 \\
\hline - No & 93.4 & 6.6 \\
\hline \multicolumn{3}{|c|}{$\begin{array}{l}\text { Sensitivity and empathy to patient requests and } \\
\text { complaints and concerns? }(\mathrm{n}=390)\end{array}$} \\
\hline - Yes & 349.0 & 41.0 \\
\hline - No & 89.5 & 10.5 \\
\hline \multicolumn{3}{|c|}{$\begin{array}{l}\text { Overall assessment of health service provider attitude } \\
\text { or disposition of health care under NHIA }(n=392)\end{array}$} \\
\hline - poor & 14.0 & 3.6 \\
\hline - average & 145.0 & 37.0 \\
\hline - good & 190.0 & 48.5 \\
\hline - excellent & 29.0 & 7.4 \\
\hline \multicolumn{3}{|c|}{$\begin{array}{l}\text { Weather respondent will refer colleagues to facility } \\
\text { for similar service? }(n=385)\end{array}$} \\
\hline - Yes & 322.0 & 63.0 \\
\hline - No & 83.6 & 16.4 \\
\hline
\end{tabular}




\section{Discussion}

Examining the relationship among sociodemographic factors, perceptions of care and service utilisation is key to maintaining client commitment and continued enrolment unto the National health insurance. This study used a questionnaire to examine how National health insurance card bearers utilised health service in relation to the socio-demographic factors and perceptions of service quality.

Although the NHIS has seen improvement in enrolment over the years (Boateng and Awunyor-Vitor, 2013), there is still the need to access client's satisfaction and utilization of healthcare with their NHIS cards.

This study shows that majority of subscribers assessed healthcare with their cards whereas 8\% (32/400) of them had never accessed healthcare with their NHIS cards since they registered with the scheme. Though a marginal proportion of respondents had never used their NHIS card since they registered, there remain an minimal $2.94 \%(12 / 400)$ subscribers who attributed their inability to access health care with their NHIS card to difficulty in getting money to renew. Another 5.8\% (23/400) of subscribers cited low quality of service provision to the reasons why they did not access health acre with their NHIS card. Other reasons why subscribers were not accessing health care with their NHIS included not falling sick and low quality of recently registering under the NHIS. This indicates financial difficulty in terms of registering under NHIS together with failure to meet clients' expectation about service quality at the various facilities contributed to the decision not to utilize health care with their NHIS cards; however, this does not significantly determine utilisation of health care with NHIS card. The findings corroborate (Boateng and Awunyor-Vitor, 2013) that income levels and poverty did not significantly influence health care access with NHIS card and contrast the positions of Jehu-Appiah (Aryeetey et al., 2010; Basaza et al., 2004) and WHO (2010).

Previous studies (Boateng and Awunyor-Vitor, 2013; Agyei-Baffour et al., 2013), report that demand for health care is determined by the quality of service provided and that even poor households limit their demand for health care when the services are poor quality, but are less sensitive to changes in quality of service (Boateng and Awunyor-Vitor, 2013). A study by (De Allegri et al., 2006a) in rural West Africa also observed that understanding consumer preferences and incorporating them into the design of community-based insurance schemes may result in increased participation rates, ensuring the poor gain better access, but they conclude that this has not been given adequate attention in existing literature.
The study further assessed the socio-demographic differences among clients who utilize healthcare with insurance cards. Client's occupation (being a student or unemployed) and residing in a rural part of the study area significantly decreased one's likelihood of accessing healthcare with NHIS card as compared to those with jobs or resided in urban areas (WHO, 2010; Bruce et al., 2008). Similar to this study, in previous studies by (Butler, 1999) the employed were more likely to undertake coverage as compared to those unemployed and this indicate that they are most likely to access healthcare with NHIS card. The study by (Boateng and Awunyor-Vitor, 2013), however found not significant association between occupation and enrolment in NHIS, a position contrasted to by this finding.

This relationship been occupation and uptake of insurance has also been investigated in previous studies where those employed were more likely to undertake coverage (Agyei-Baffour et al., 2013; Savage and Wright, 1999; Butler, 1999). This could be explained on the basis that the employed could earn income and therefore could afford the insurance premium. Again in this study, those residing in rural parts of the study setting were not likely to access healthcare with NHIS. This is supported by recent empirical evidence which reveals that the NHIS is falling short of its equity goals, with lower enrolment among the poor (Sarpong et al., 2010; Asante and Aikins, 2008; Aryeetey et al., 2010; Buor, 2004).

The extensive review by Preker and Carrin (2004) in their analytical framework, reports among other findings that the poorest of the poor and socially excluded groups are not automatically reached even though the schemes are effective in reaching a large number of low-income populations. It was also noted that high-income groups are frequently under represented relative to the entire population. The determinants of success in their review include the ability of the schemes to address adverse selection and rent-seeking provider behaviour and purchasing mechanism instruments. Majority of NHIS subscribers did not consider much difference between the insured and uninsured in terms of how much respect health staff accords them. Majority of them had positive perceptions about staffs' attitudes in terms of listening and being, sensitive to their requests and complaints. The general attitude of staffs to insured clients was rated as good and more than $80 \%$ indicated recommending NHIS to friends and colleagues citing spending less on healthcare as major reason. The findings of this study in being in tandem with (Alatinga and Williams, 2012), reported no disparity among the insured and uninsured in terms of assessing health providers on their attitude. Results from this study on perceived quality of care were similar to other studies which concluded that quality of 
health care given to clients was generally satisfactorily among both insured and non-insured (Boateng and Awunyor-Vitor, 2013; Bruce et al., 2008; Alatinga and Williams, 2012). According to (Devadasan et al., 2004; Dalinjong and Laar, 2012) a contrary finding was however identified where insured clients had a significantly higher frequency of physical examination, laboratory investigations and diabetes education compared to their uninsured.

\section{Conclusion}

The study has brought to the fore and adds to the surging studies about NHIS client satisfaction with health care accessed. The study presents that client perception has been shown to be positively related to health service utilization. There is also a positive relationship between clients' socio-demographic characteristics and their utilization of health services under the National Health Insurance Scheme. However, there were specific socio-demographic variables that were associated with accessing health care with NHIS.

The study calls for the need for due attention to be given to quality health care under the scheme so as to create good public image and a positive perception about the scheme. The government also has a core duty to examine the socio-demographic characteristics of citizens in the country so as to create favorable atmosphere that can increase utilization of health services under the scheme. Policies being enacted should consider factors such as the urban poor, the peri-urban and rural dwellers in urban districts. Thus, the scheme should be made flexible to reflect the socio-demographic features and economic conditions prevailing in the country if the equity goal of the national Health insurance scheme is to be met.

\section{Conflict of Interest}

The author declares no conflict of interest.

\section{Author's Contributions}

AS CY contributed to the overall aspect from design to drafting the article and Critical revision of the article to submission for publication.

\section{References}

Agyei-Baffour, P., R. Oppong and D. Boateng, 2013. Knowledge, perceptions and expectations of capitation payment system in a health insurance setting: A repeated survey of clients and health providers in Kumasi, Ghana. BMC Public Health, 13: 1220-1220. DOI: 10.1186/1471-2458-13-1220
Akazili, J., F. Anto, T. Anoyoriga et al., 2005. The perception and demand for mutual health insurance in the Kassena-Nankana district of northern Ghana. Project Number:2002/GD/17. The Ghanaian-Dutch Collaboration for Health Research and Development.

Alatinga, K.A. and J.J. Williams, 2012. Does membership in mutual health insurance guarantee quality health care? Some evidence from Ghana. Eur. J. Bus. Soc. Sci., 1: 103-118

Arhinful, D., 2003. The solidarity of self-interest: Social and cultural feasibility of rural health insurance in Ghana. Leiden, Netherlands. African Studies Centre.

Aryeetey, G.C., C. Jehu-Appiah, E. Spaan, B. D'Exelle and I. Agyepong, 2010. Identification of poor households for premium exemptions in Ghana's National Health Insurance Scheme: Empirical analysis of three strategies. Tropical Med. Int. Health 15: 1544-52.

DOI: $10.1111 /$ j.1365-3156.2010.02663.x

Asante, F. and M. Aikins, 2008. Does the NHIS cover the poor? Danida Health Sector Support Office paper. Accra, Ghana: Danida

Asenso-Okyere, W.K., I. Osei-Akoto, A. Anum and E.N. Appiah, 1997. Willingness to pay for health insurance in a developing economy. A pilot study of the informal sector of Ghana using contingent valuation. Health Policy, 42: 223-237. DOI: 10.1016/S0168-8510(97)00069-9

Assensoh, A.B. and H. Wahab, 2008. A historical-cumpolitical overview of Ghana's national health insurance law. African Asian Stud., 7: 2-3.

Basaza, R., B. Criel and P. Van Der Stuyft, 2008. Community health insurance in Uganda: Why does enrolment remain low? A View From Beneath. Health Policy, 87: 172-184.

DOI: $10.1016 /$ j.healthpol.2007.12.008

Boateng, D. and D. Awunyor-Vitor, 2013. Health insurance in Ghana: Evaluation of policy holders' perceptions and factors influencing policy renewal in the Volta region. Int. J. Equity Health, 12: 1-10. DOI: $10.1186 / 1475-9276-12-50$

Bruce, K., S.A. Narh-Bana and A. Agyepong, 2008. Community satisfaction, equity in coverage and implications for sustainability of the Dangme West Health Insurance Scheme. Technical Report Series No 9. Ghana-Dutch collaboration for health research and development.

Buor, D., 2004. Determinants of utilization of health services by women in rural and urban areas in Ghana. Geo J., 61: 89-102.

Buor, D., 2004. Gender and the utilisation of health services in the ashanti region, Ghana. Health Policy, 69: 375-388. DOI: 10.1016/j.healthpol.2004.01.004 
Butler, J., 1999. Estimating Elasticities of Demand for Private Health Insurance in Australia. 1st Edn., National Centre for Epidemiology and Population Health, Canberra.

Butler, J.R.G., 1999. Estimating elasticities of demand for private health insurance in Australia. National Centre for Epidemiology and Population Health.

Dalinjong, P.A. and A.S. Laar, 2012. The national health insurance scheme: Perceptions and experiences of health care providers and clients in two districts of Ghana. Health Econom. Rev., 2: 1-13.

DOI: $10.1186 / 2191-1991-2-13$

Dalinjong, P.A. and A.S. Laar, 2012. The national health insurance scheme: Perceptions and experiences of health care providers and clients in two districts of Ghana. Health Econom. Rev., 2: 1-13.

DOI: $10.1186 / 2191-1991-2-13$

De Allegri, M., B. Kouyaté, H. Becher, A. Gbangou and S. Pokhrel et al., 2006b. Understanding enrolment in community health insurance in subsaharan Africa: A population-based case-control study in rural burkina faso. Bull. World Health Organiz., 84: 852-858.

De Allegri, M., M. Sanon and R. Sauerborn, 2006a. "To enrol or not to enrol?": A qualitative investigation of demand for health insurance in rural West Africa. Soc. Sci. Med., 2: 1520-1527. DOI: 10.1016/j.socscimed.2005.07.036

Devadasan, N., K. Ranson, W.V. Damme and B. Criel, 2004. Community Health Insurance in India, an overview. Economic and Political Weekly.

Dong, H., M. De Allegri, D. Gnawali, A. Souares and R. Sauerborn, 2009. Drop-out analysis of communitybased health insurance membership at nouna, burkina faso. Health Policy, 92: 174-179. DOI: 10.1016/j.healthpol.2009.03.013

Haran, B., T. Lavy, J. Shemer and S. Shani, 2000. Regulation of natural medicines in israel and Abroad]. Harefuah, 139: 339.

Kamuzora, P. and L. Gilson, 2007. Factors influencing implementation of the community health fund in Tanzania. Health Policy Plann., 22: 95-102. DOI: 10.1093/heapol/czm001

Lee, C.H., C.L. Cheng, Y.H.Y. Kao, S.J. Lin and M.L. Lai, 2011. Validation of the national health insurance research database with ischemic stroke cases in Taiwan. Pharmacoepidemiol. Drug Safety, 20: 236-242. DOI: $10.1002 /$ pds. 2087

Liu, T.C. and C.S. Chen, 2002. An analysis of private health insurance purchasing decisions with national health insurance in Taiwan. Soc. Sci. Med., 55: 755-774. DOI: 10.1016/S0277-9536(01)00201-5
Ndiaye, P., W. Soors and B. Criel, 2007. Editorial: A view from beneath: Community health insurance in Africa. Tropical Med. Int. Health, 12: 157-161. DOI: $10.1111 /$ j.1365-3156.2007.01814.x

NDPC, 2009. Citizens' Assessment of the National Health Insurance Scheme, Towards a sustainable Health Care Financing Arrangement that protects the Poor, Implementation of the GPRS II (2006-2009).

Nketiah-Amponsah, E., 2009. Demand for health insurance among women in Ghana: Cross-sectional evidence.

Preker, A.S. and G. Carrin, 2004. Health finansing for poor people: Resource mobilization and risk sharing. World Bank.

Ross, C.E. and J. Mirowsky, 2000. Does medical insurance contribute to socioeconomic differentials in health? Milbank Q., 78: 291-321. DOI: $10.1111 / 1468-0009.00171$

Sarpong, N., W. Loag, J. Fobil, C. Meyer and Y. Adu-Sarkodie et al., 2010. National health insurance coverage and socio-economic status in a rural district of Ghana. Tropical Med. Int. Health, 15: 191-197. DOI: 10.1111/j.1365-3156.2009.02439.x

Savage, E. and D. Wright, 1999. Health insurance and health care utilization: Theory and evidence from Australia 1989-90. University of Sydney, Sydney.

Sinha, T., M.K. Ranson, M. Chatterjee, A. Acharya and A.J. Mills, 2006. Barriers to accessing benefits in a community-based insurance scheme: Lessons learnt from sewa insurance, Gujarat. Health Policy Plann., 21: 132-142. DOI: 10.1093/heapol/czj010

Trujillo, A.J., 2003. Medical care use and selection in social health insurance with an equalization fund: Evidence from Colombia. Health Econ., 12: 231-246.

Turkson, P.K., 2009. Perceived quality of healthcare delivery in a rural district of Ghana. Ghana Med. J., 43: 65-70.

WHO, 2006. Quality of care. A process for making strategic choices in health systems WHO Library Cataloguing-in-Publication Data. WHO 2006, Geneva.

WHO, 2010. Obstacle in the process of establishing a sustainable National Health Insurance Scheme. A technical Brief for Policy-Makers, Ghana.

Wiesmann, D. and J. Jütting, 2001. Determinants of viable health insurance schemes in rural subSaharan Africa. Q. J. Int. Agric., 50: 361-378. 